\title{
Toward Ideal Arene Assembly: Catalytic C-H Bond Arylation of Aromatic Compounds
}

\author{
Kenichiro Itami \\ Department of Chemistry, Graduate School of Science, Nagoya University \\ Nagoya 464-8602, Japan
}

(Received June 28, 2010; E-mail: itami@chem.nagoya-u.ac.jp)

\begin{abstract}
In this account, the early stages of our campaign (2006-2009) to develop catalysts able to realize ideal arene assembly through catalytic $\mathrm{C}-\mathrm{H}$ bond arylation of aromatic compounds are described. New $\mathrm{Rh}$, Ir, and $\mathrm{Ni}$ catalysts have been developed for the $\mathrm{C}-\mathrm{H}$ bond arylation of heteroarenes with haloarenes. It was also found that $\mathrm{Cu}\left(\mathrm{OCOCF}_{3}\right)_{2}$ can promote the $\mathrm{C}-\mathrm{H}$ bond arylation of electron-rich arenes with aryl boronic acids. During these studies, we accidentally discovered that $\mathrm{KO} t-\mathrm{Bu}$ alone can promote the $\mathrm{C}-\mathrm{H}$ bond arylation of electron-deficient nitrogen heterocycles with haloarenes. Through a sequence of three consecutive bond-selective $\mathrm{C}-\mathrm{H}$ arylations, a programmed synthesis of tetraarylthiophenes has been established. During this study, we discovered metal-and ligand-controlled regiodivergency in $\mathrm{C}-\mathrm{H}$ bond arylation.
\end{abstract}

\section{Introduction}

Organic molecules having aryl-aryl bonds (arene-assembled molecules) represent privileged structural motifs frequently found in natural products or used in pharmaceuticals and functional organic materials. Therefore, the development of efficient methods for biaryl formation has been a topic of utmost importance in all areas of pure and applied chemistry. ${ }^{1}$ Although the $\mathrm{Pd}$-catalyzed cross-coupling reactions of metalated arene/heteroarene and halogenated arene/heteroarene species are undoubtedly among the most reliable methods for making biaryls and heterobiaryls, ${ }^{1}$ the $\mathrm{C}-\mathrm{H}$ bond arylation of arenes and heteroarenes holds significant potential for streamlining overall synthetic routes (Scheme 1). ${ }^{2,3}$ The importance of such processes is also apparent from the significance of catalytic $\mathrm{C}-\mathrm{H}$ bond functionalization in chemical synthesis. ${ }^{4}$ Indeed, the quest for such methods has been the driving force behind enormous efforts in the synthetic community including our group, culminating in a wealth of useful

Scheme 1. Arene-assembling reactions through $\mathrm{C}-\mathrm{H}$ bond functionalization.

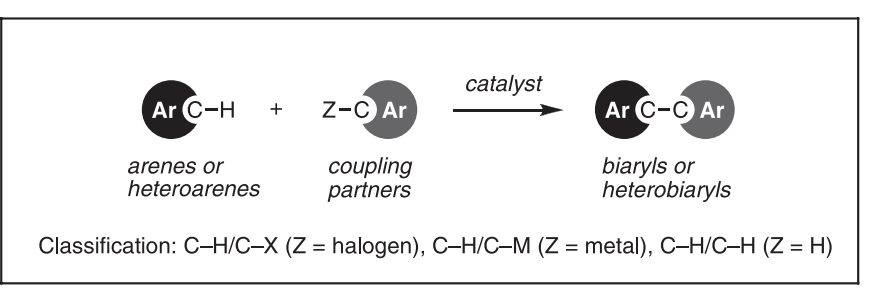

Catalysts and Promoters Developed in Our Group (2006 2009)

$$
\begin{gathered}
\mathrm{P}\left[\mathrm{OCH}\left(\mathrm{CF}_{3}\right)_{2}\right]_{3} \\
\mathrm{Cl}-\mathrm{Rh}-\mathrm{CO} \\
1 \\
\mathrm{P}\left[\mathrm{OCH}\left(\mathrm{CF}_{3}\right)_{2}\right]_{3}
\end{gathered}
$$

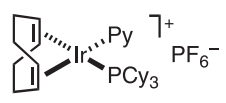

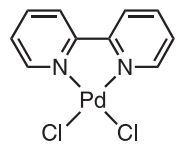

$\mathrm{KO} t-\mathrm{Bu}$

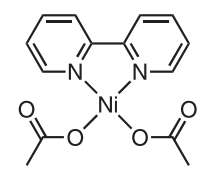<smiles>CC(=O)O[N+](OC(C)=O)(P(c1ccccc1)c1ccccc1)P(c1ccccc1)c1ccccc1</smiles>

catalytic systems for reactions assembling arenes through $\mathrm{C}-\mathrm{H}$ bond functionalization. ${ }^{2}$ The $\mathrm{C}-\mathrm{H}$ bond arylations of arenes can be formally classified into the following three types; (i) $\mathrm{C}$ $\mathrm{H} / \mathrm{C}-\mathrm{X}$ biaryl coupling, (ii) $\mathrm{C}-\mathrm{H} / \mathrm{C}-\mathrm{M}$ biaryl coupling, and (iii) $\mathrm{C}-\mathrm{H} / \mathrm{C}-\mathrm{H}$ biaryl coupling. In this account, we describe the early stages of our campaign (2006-2009) to develop catalysts able to realize ideal arene assembly through the catalytic $\mathrm{C}-\mathrm{H}$ bond arylation of aromatic compounds (Scheme 1).

\section{Our Motivation: Synthesis of Triarylpyrimidines}

Multiply arylated heterocycles are privileged structures with many interesting functions and fascinating optoelectronic or biological properties. In order to accelerate the discovery and structure-property relationship studies of new functional molecules of this class, there is a great need for a flexible method for accessing all possible isomers in a programmable manner. Driven by this consideration, we have established the general synthetic scheme for 2,4,6-triarylpyrimidines shown in Scheme 2. ${ }^{5}$ Moreover, from the triarylpyrimidine library created, we were able to identify several interesting fluorescent materials and some with properties such as solvatofluorochromism. ${ }^{5}$

Although our simple organometallic-based protocol successfully demonstrated the power of a programmable and diversity-oriented synthetic strategy in materials science, the methods we had used were far from ideal; converting a hydrogen atom on the pyrimidine ring to an aryl group required a multi-step synthesis (organolithium addition, protonation, and oxidation by DDQ). ${ }^{5}$ This naturally led us to decide on the direct $\mathrm{C}-\mathrm{H}$ bond arylation of heterocycles as an ideal method for making multiply arylated heterocycles. Therefore, in 2004, we initiated our studies on the development of a programmable synthesis of arylated thiophenes and thiazoles using several $\mathrm{C}-\mathrm{H}$ bond arylation reactions known at that time. ${ }^{6}$ These, however, met with limited success, ${ }^{7}$ which encouraged us instead to develop new and efficient catalytic systems for arene-assembling reactions through $\mathrm{C}-\mathrm{H}$ bond functionalization. 
Scheme 2. Synthesis and properties of triarylpyrimidines. General Synthesis of Triarylpyrimidines
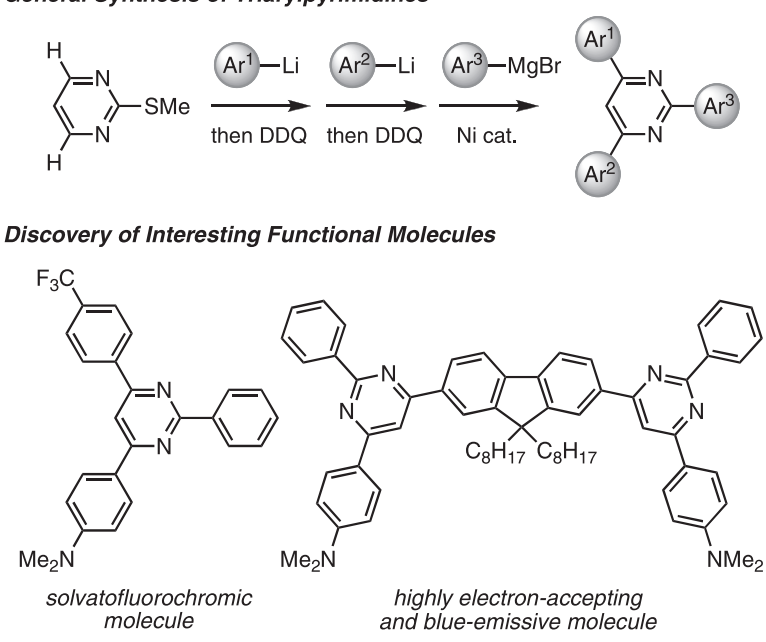

Problem in Synthesis: Motivation for Direct $\mathrm{C}-\mathrm{H}$ Bond Arylation

$$
\text { Ideal: Direct C-H Bond Arylation? }
$$

\section{Rhodium-Catalyzed C-H/C-X Biaryl Coupling}

Our initial scenario for realizing an efficient transition metal-catalyzed biaryl coupling of arenes with haloarenes $(\mathrm{C}-$ $\mathrm{H} / \mathrm{C}-\mathrm{X}$ biaryl coupling) has been the redox-catalysis shown in Scheme $3{ }^{8}$ This involves (i) oxidative addition of haloarene (Ar-X) to transition metal complex (M), (ii) electrophilic metalation of arene $(\mathrm{Ar}-\mathrm{H})$ with thus-formed $\mathrm{Ar}-\mathrm{M}-\mathrm{X}$ giving diarylmetal species, and (iii) reductive elimination of biaryl product $(\mathrm{Ar}-\mathrm{Ar})$ with the regeneration of catalyst $\mathrm{M}$. We envisaged that the use of electron-withdrawing neutral ligand would lead to a distinct nucleophile-electrophile interaction between an arene $(\mathrm{Ar}-\mathrm{H})$ and $\mathrm{Ar}-\mathrm{M}-\mathrm{X}$ species, thereby promoting electrophilic arene metalation. In addition, we also

Scheme 3. Our initial strategy for $\mathrm{C}-\mathrm{H} / \mathrm{C}-\mathrm{X}$ biaryl coupling and discovery of Rh catalyst $\mathbf{1}$.

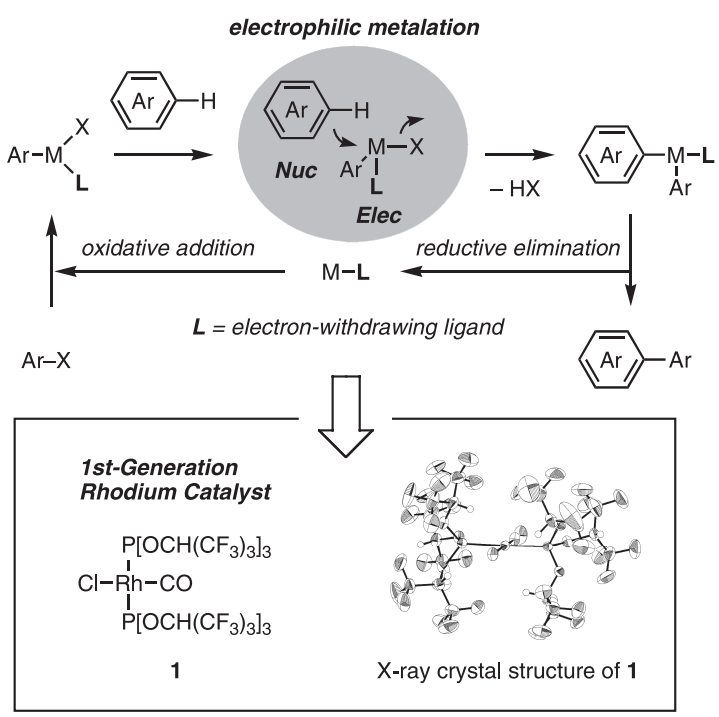

expected such a ligand to facilitate the product-forming reductive elimination step. This mechanistic blueprint means our designed $\mathrm{C}-\mathrm{H} / \mathrm{C}-\mathrm{X}$ biaryl coupling should best be described as a 'Friedel-Crafts' aromatic arylation reaction.

In order to find an as-yet unexplored catalyst of this kind, we took a very distinct and unconventional approach. Rather than screening various ligands for a transition metal, we screened transition metals by fixing the ligand as $\mathrm{P}\left[\mathrm{OCH}\left(\mathrm{CF}_{3}\right)_{2}\right]_{3}$ which is known to be one of the most electronwithdrawing neutral ligands. ${ }^{9}$ After extensive screening, we were able to identify that $\mathrm{Rh}^{10}$ is a central metal of choice, able to realize our concept, and that $\mathrm{RhCl}(\mathrm{CO})\left\{\mathrm{P}\left[\mathrm{OCH}\left(\mathrm{CF}_{3}\right)_{2}\right]_{3}\right\}_{2}$ (1) is a bench-stable catalyst precursor (Scheme 3). ${ }^{8}$ The complex 1 can be prepared quantitatively by mixing $\left[\mathrm{RhCl}(\mathrm{CO})_{2}\right]_{2}$ and $\mathrm{P}\left[\mathrm{OCH}\left(\mathrm{CF}_{3}\right)_{2}\right]_{3}$ in toluene. A notable feature of this complex is its outstanding stability to air and moisture in the solid state. Virtually no decomposition of $\mathbf{1}$ has been detected after extended ( $>10$ months) exposure to air. The $\mathrm{X}^{-}$ ray crystal structure of $\mathbf{1}$ indicates that this may be partly due to effective shielding of the $\mathrm{Rh}$ atom by two bulky phosphite ligands (Scheme 3).

Rhodium complex 1, with the assistance of silver carbonate, catalyzed the $\mathrm{C}-\mathrm{H} / \mathrm{C}-\mathrm{X}$ biaryl coupling of electron-rich heteroarenes and iodoarenes (Scheme 4). ${ }^{8}$ Thiophenes, furans, pyrroles, and indoles were applicable as heteroarene coupling partners. For all thiophenes and furans examined, the coupling proceeded selectively at carbons adjacent to sulfurs or oxygens. When 1-phenylpyrrole was used as a substrate, the $\mathrm{C}-\mathrm{H}$ coupling took place selectively at the $3-$ position of the pyrrole ring. The coupling of 1-methylindole took place at both $\mathrm{C} 2$ and $\mathrm{C} 3$ positions, though favoring the C3-arylation product.

Scheme 4. $\mathrm{Rh}-$ catalyzed $\mathrm{C}-\mathrm{H} / \mathrm{C}-\mathrm{X}$ biaryl coupling.
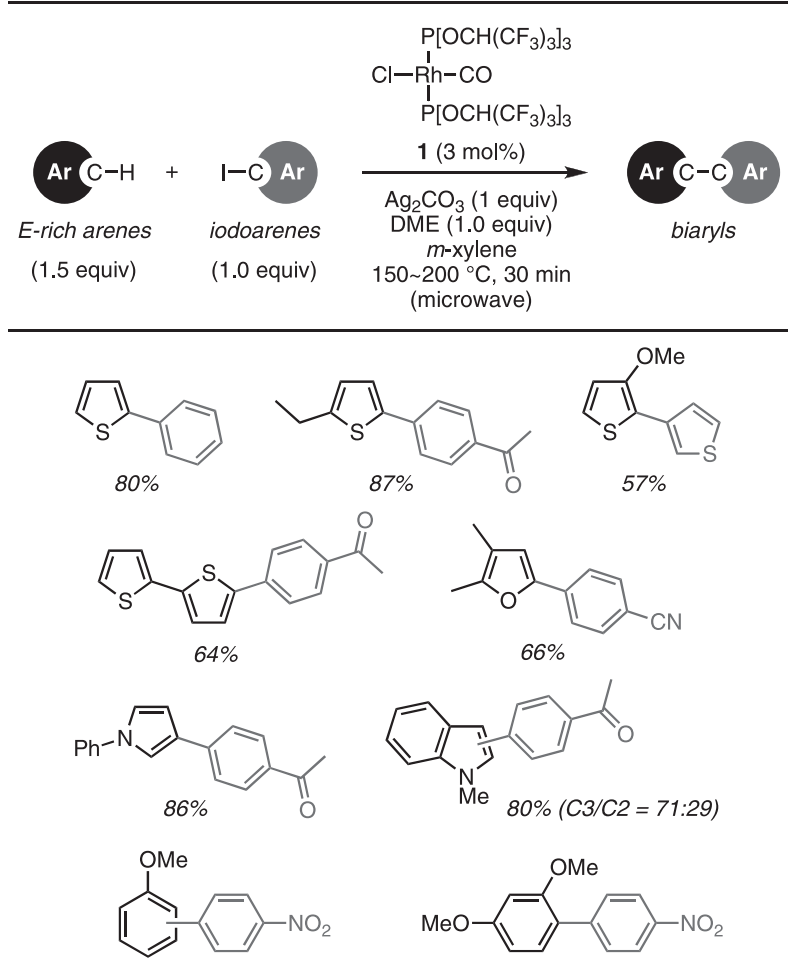

$51 \%(o / p=29: 71)$

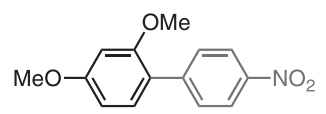

$76 \%$ 
Although the $\mathrm{C}-\mathrm{H}$ coupling did not proceed with electrondeficient heteroarenes such as pyridine, we found that $\mathrm{Rh}$ catalyst $\mathbf{1}$ can effect the direct $\mathrm{C}-\mathrm{H}$ bond arylation of benzene derivatives, which have proven to be the most challenging substrate class in this field (Scheme 4). ${ }^{8}$ For example, when anisole was treated with $p$-nitrophenyl iodide, arylated anisoles were obtained as a mixture of regioisomers $(51 \%$ yield; $o: m: p=29: 0: 71$ ). When 1,3-dimethoxybenzene was used as a substrate, arylation occurred exclusively at the 4-position giving the corresponding biaryl in $76 \%$ yield. These reactions not only serve as successful examples of the functionalization of relatively simple benzene derivatives, but also shed some light on the mechanism. The manifestation of clear ortho-para selectivity in the arylation of alkoxybenzenes is consistent with the proposed $\mathrm{C}-\mathrm{H}$ bond cleavage based on electrophilic metalation (Scheme 3). ${ }^{8}$

In line with our mechanistic assumption that the use of an electron-withdrawing ligand such as $\mathrm{P}\left[\mathrm{OCH}\left(\mathrm{CF}_{3}\right)_{2}\right]_{3}$ has a significant impact on the energy profile of the catalytic cycle, we observed a strong ligand effect in the present catalysis. For example, when a less $\pi$-accepting ligand such as $\mathrm{P}\left(\mathrm{C}_{6} \mathrm{H}_{5}\right)$ $\left[\mathrm{OCH}\left(\mathrm{CF}_{3}\right)_{2}\right]_{2}, \mathrm{P}\left(\mathrm{OC}_{6} \mathrm{H}_{5}\right)_{3}, \mathrm{P}\left[\mathrm{OCH}\left(\mathrm{CH}_{3}\right)_{2}\right]_{3}$, or $\mathrm{P}\left(\mathrm{C}_{6} \mathrm{H}_{5}\right)_{3}$ was used in place of $\mathrm{P}\left[\mathrm{OCH}\left(\mathrm{CF}_{3}\right)_{2}\right]_{3}$, the yield of arylation product decreased dramatically (Table 1 ). There is a clear correlation between the arylation efficiency and the $\pi$-accepting ability of the ligand, as judged by electronic parameters ${ }^{11}$ based on the carbonyl stretching frequency $\left(v_{\mathrm{CO}}\right)$ in trans $-\mathrm{RhCl}(\mathrm{CO}) \mathrm{L}_{2}$ complexes. In particular, the dramatic difference between $\mathrm{P}\left[\mathrm{OCH}\left(\mathrm{CF}_{3}\right)_{2}\right]_{3}$ and $\mathrm{P}\left[\mathrm{OCH}\left(\mathrm{CH}_{3}\right)_{2}\right]_{3}$, which are almost identical in size, is a clear indication that the $\pi$-accepting nature of the ancillary ligand is of the greatest benefit in our catalysis.

Table 1. Effect of ligand in $\mathrm{Rh}-$ catalyzed $\mathrm{C}-\mathrm{H} / \mathrm{C}-\mathrm{X}$ coupling.

\begin{tabular}{|c|c|c|}
\hline $\int^{\mathrm{OMe}}+$ & $\begin{array}{r}\begin{array}{r}\mathrm{Rh} \\
(3 \\
\mathrm{Ag}_{2} \mathrm{CC}\end{array} \\
m \\
\begin{array}{r}200 \\
(\mathrm{mi}\end{array}\end{array}$ & 11 \\
\hline ligand $(L)$ & yield & $v_{\mathrm{CO}}$ in $\mathrm{RhCl}(\mathrm{CO}) \mathrm{L}_{2}$ \\
\hline $\mathrm{P}\left[\mathrm{OCH}\left(\mathrm{CF}_{3}\right)_{2}\right]_{3}$ & $94 \%$ & $2070 \mathrm{~cm}^{-1}$ \\
\hline $\mathrm{P}\left(\mathrm{C}_{6} \mathrm{H}_{5}\right)\left[\mathrm{OCH}\left(\mathrm{CF}_{3}\right)_{2}\right]_{2}$ & $31 \%$ & $2038 \mathrm{~cm}^{-1}$ \\
\hline $\mathrm{P}\left(\mathrm{OC}_{6} \mathrm{H}_{5}\right)_{3}$ & $6 \%$ & $2018 \mathrm{~cm}^{-1}$ \\
\hline $\mathrm{P}\left[\mathrm{OCH}\left(\mathrm{CH}_{3}\right)_{2}\right]_{3}$ & $9 \%$ & $2002 \mathrm{~cm}^{-1}$ \\
\hline $\mathrm{P}\left(\mathrm{C}_{6} \mathrm{H}_{5}\right)_{3}$ & $0 \%$ & $1983 \mathrm{~cm}^{-1}$ \\
\hline
\end{tabular}

\section{Iridium-Catalyzed C-H/C-X Biaryl Coupling}

In our $\mathrm{Rh}$ catalysis, the generation of cationic $\mathrm{Rh}$ intermediates and the unique role of $\mathrm{Ag}_{2} \mathrm{CO}_{3}$ have been identified as keys to success by experimental and theoretical studies. Expecting a similar mode of catalysis with higher efficiency, we set out to investigate the cationic $\operatorname{Ir}(\mathrm{I}) / \mathrm{Ag}_{2} \mathrm{CO}_{3}$ system as a new platform for $\mathrm{C}-\mathrm{H}$ bond arylation of arenes. ${ }^{12}$ Thus, we began by investigating the effect of ligand using $\left[\operatorname{Ir}(\operatorname{cod})_{2}\right] \mathrm{BF}_{4}$ as a source of cationic $\operatorname{Ir}(\mathrm{I})$ species. ${ }^{13}$ In contrast to $\mathrm{Rh}$ catalysis, our original ligand $\mathrm{P}\left[\mathrm{OCH}\left(\mathrm{CF}_{3}\right)_{2}\right]_{3}$ proved to be ineffective as a ligand. Further screening of ligands indicated that $\mathrm{PCy}_{3}$ was by far the most effective. In developing a stable $\mathrm{Ir}^{+} / \mathrm{PCy}_{3}$ precatalyst, we identified $\left[\operatorname{Ir}(\mathrm{cod})(\mathrm{py}) \mathrm{PCy}_{3}\right] \mathrm{PF}_{6} \quad$ (2: Crabtree's catalyst $^{14}$ ) to be very convenient. Interestingly, the corresponding rhodium complex $\left[\mathrm{Rh}(\operatorname{cod})(\mathrm{py}) \mathrm{PCy}_{3}\right] \mathrm{PF}_{6}$ was totally ineffective. The importance of $\mathrm{Ag}_{2} \mathrm{CO}_{3}$ was also recognized, as other additives, such as AgOTf, AgOAc, $\mathrm{AgSbF}_{6}, \mathrm{Na}_{2} \mathrm{CO}_{3}$, $\mathrm{K}_{2} \mathrm{CO}_{3}, \mathrm{Cs}_{2} \mathrm{CO}_{3}$, and $\mathrm{KO} t-\mathrm{Bu}$, did not promote the reaction when the $\mathrm{Ir}^{+} / \mathrm{PCy}_{3}$ catalyst was used.

Under the influence of $\left[\operatorname{Ir}(\operatorname{cod})(\mathrm{py}) \mathrm{PCy}_{3}\right] \mathrm{PF}_{6}$ catalyst (2) and $\mathrm{Ag}_{2} \mathrm{CO}_{3}$, a range of electron-rich heteroarenes underwent $\mathrm{C}-\mathrm{H}$ bond arylation with electronically and structurally diverse iodoarenes in $m$-xylene at $160{ }^{\circ} \mathrm{C}$ (Scheme 5). ${ }^{13}$ Efficient coupling proceeded even using equimolar quantities of each coupling partner. Thiophenes, furans, pyrroles, indoles, and benzothiophenes were applied as the heteroarene coupling partner. In all cases examined, arylation took place in a regioselective fashion; at the $\alpha$-positions for thiophenes, furans, pyrroles, 2-positions for benzothiophenes, and 3-positions for indoles. Notably, $\mathrm{Br}$-containing substrates underwent $\mathrm{C}-\mathrm{H}$ bond arylation while leaving the $\mathrm{C}-\mathrm{Br}$ bond intact, which is attractive for further synthetic elaboration.

Scheme 5. Ir-catalyzed $\mathrm{C}-\mathrm{H} / \mathrm{C}-\mathrm{X}$ biaryl coupling.
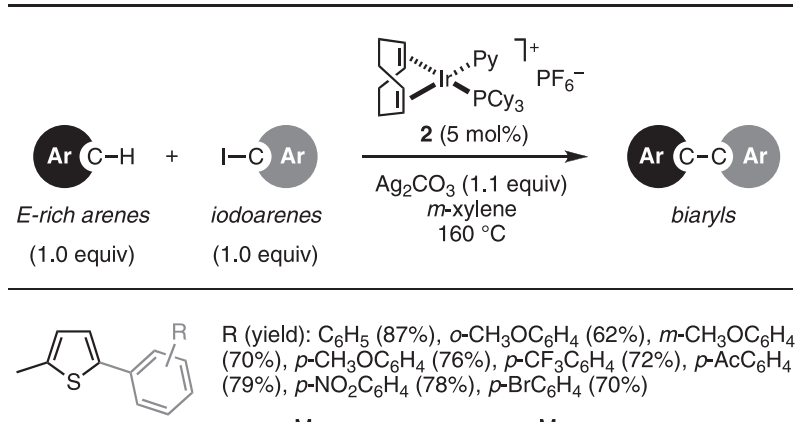<smiles>COc1ccc(-c2ccccc2)s1</smiles><smiles>Cc1cc(-c2ccccc2)sc1Br</smiles><smiles>Cc1cc(-c2ccc(C#N)cc2)oc1C</smiles>
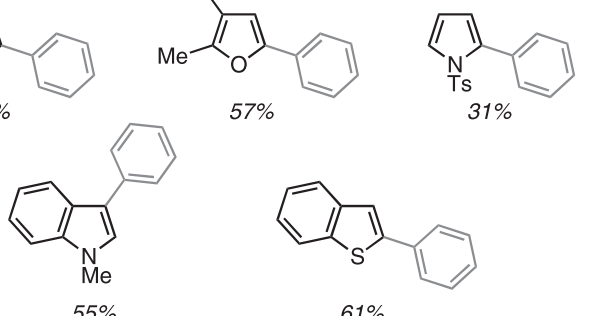

$57 \%$

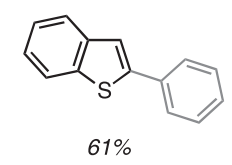

In view of the efficient aryl-aryl bond formation achieved, this Ir catalysis should have broad potential for the construction of a range of extended $\pi$-electron systems (Scheme 6). ${ }^{13}$ For example, when 1,4-diiodobenzene was treated with an excess amount of 2-methylthiophene, a twofold $\mathrm{C}-\mathrm{H}$ bond arylation occurred giving the thiophene-benzene-thiophene triad in $86 \%$ yield. A meta-linked isomer was also obtained by the reaction using 1,3-diiodobenzene as the coupling partner. Double $\mathrm{C}-\mathrm{H}$ bond arylation at the same heteroarene core was also achieved. For example, when 3-methoxythiophene was treated with an excess amount of iodobenzene, a double $\mathrm{C}-\mathrm{H}$ bond arylation of the thiophene core took place at the 2- and 5-positions, furnishing the benzene-thiophene-benzene triad in $66 \%$ yield.

Although the mechanism of this $\mathrm{Ir}-$ catalyzed reaction remains unknown, one possibility involves $\operatorname{Ir}^{\mathrm{I}} / \mathrm{Ir}^{\mathrm{III}}$ redox cata- 
Scheme 6. Multiple $\mathrm{C}-\mathrm{H}$ bond arylation producing extended $\pi$-systems

Twofold C-H Bond Arylation

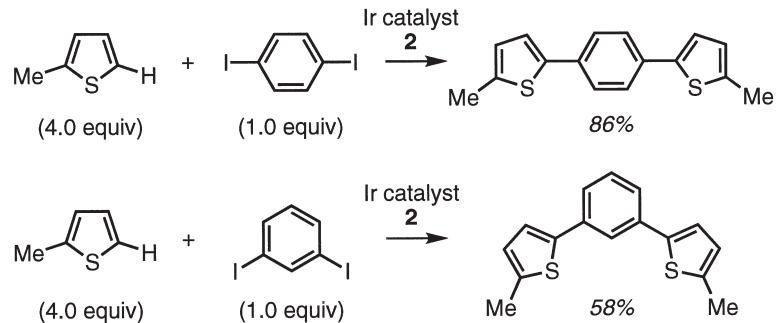

\section{Double C-H Bond Arylation}<smiles>COc1cccs1</smiles>

(1.0 equiv)

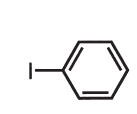

(4.0 equiv)

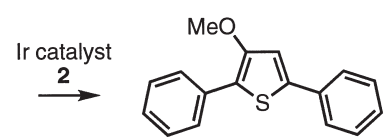

$66 \%$ lysis initiated by the oxidative addition of $\mathrm{Ar}-\mathrm{I}$ to a cationic $\mathrm{Ir}^{\mathrm{I}}$ complex yielding an $\left[\mathrm{Ar}-\mathrm{Ir}^{\mathrm{III}}-\mathrm{I}\right]^{+}$species. Subsequently, abstraction of iodide by $\mathrm{Ag}_{2} \mathrm{CO}_{3}$ could take place to generate a highly electrophilic $\left[\mathrm{Ar}-\mathrm{Ir}^{\mathrm{III}}\right]^{2+}$ species, which might react by electrophilic metalation of heteroarene $(\mathrm{Het}-\mathrm{H})$. The resulting $\left[\mathrm{Ar}-\mathrm{Ir}^{\mathrm{III}}-\mathrm{Het}\right]^{+}$intermediate could then undergo heteroarylaryl reductive elimination, furnishing a heterobiaryl with concurrent regeneration of the cationic $\operatorname{Ir}^{\mathrm{I}}$ complex. A preliminary kinetic isotope effect study was also performed. From the inter-and intramolecular competitive reactions of deuteriumlabeled thiophenes with iodobenzene, the $k_{\mathrm{H}} / k_{\mathrm{D}}$ value for thiophene arylation was estimated to be $1.9 .^{13}$

\section{Nickel-Catalyzed C-H/C-X Biaryl Coupling}

Although we had established unique catalytic systems based on $\mathrm{Rh}$ and Ir, we were not completely satisfied since both $\mathrm{Rh}$ and Ir complexes are quite expensive. Naturally, we put efforts geared toward the use of inexpensive metal catalysts for $\mathrm{C}-\mathrm{H} / \mathrm{C}-\mathrm{X}$ biaryl coupling. ${ }^{15}$ Thus, we began by examining various inexpensive metal salts, ligands, and additives for the $\mathrm{C}-\mathrm{H} / \mathrm{C}-\mathrm{X}$ biaryl coupling of heteroarenes and aryl electrophiles. After extensive screening, we uncovered the fact that nickel effectively catalyzes the coupling of azoles and aryl electrophiles (Scheme 7). ${ }^{15,16}$ In view of its efficiency, cost, simplicity, and stability, we identified $\mathrm{Ni}(\mathrm{OAc})_{2}$ to be the catalyst precursor of choice. ${ }^{17}$ Among various parameters investigated, the choice of basic additive turned out to be critical: when $\mathrm{LiO} t-\mathrm{Bu}$ was replaced by other bases such as $\mathrm{NaO} t-\mathrm{Bu}, \mathrm{KO} t-\mathrm{Bu}, \mathrm{NaOMe}, \mathrm{LiOH}, \mathrm{Li}_{2} \mathrm{CO}_{3}, \mathrm{Cs}_{2} \mathrm{CO}_{3}$, or $\mathrm{DBU}$, essentially none of the target biaryl product was produced.

$\mathrm{Ni}(\mathrm{OAc})_{2} / 2,2^{\prime}$-bipyridyl (bipy) serves as a general catalyst for the $\mathrm{C}-\mathrm{H} / \mathrm{C}-\mathrm{X}$ biaryl coupling of azoles and aryl bromides/ iodides in $1,4-$ dioxane at $85^{\circ} \mathrm{C}$. Benzothiazole, thiazole, benzoxazole, oxazole, and $N$-methylbenzimidazole were found to be applicable heteroarenes (azoles). Various electronically and structurally diverse aryl bromides/iodides were applicable as the aryl electrophile partner, and both electron-rich and electron-deficient aryl bromides/iodides could be used. The severe steric hindrance imposed by ortho-substitution was tolerated. Heteroaryl iodides and bromides were also reactive. The reaction also took place with catalyst loading as low as 1 $\mathrm{mol} \%$ of Ni. For the coupling using more challenging aryl electrophiles such as chlorides and triflates, $\mathrm{Ni}(\mathrm{OAc})_{2} / \mathrm{dppf}$ showed catalytic activity at $140{ }^{\circ} \mathrm{C}$.

To demonstrate the synthetic utility of this $\mathrm{Ni}$-catalyzed $\mathrm{C}-\mathrm{H} / \mathrm{C}-\mathrm{X}$ biaryl coupling, a rapid synthesis of febuxostat was examined (Scheme 8). ${ }^{15}$ Febuxostat is a novel, nonpurine,

Scheme 7. Ni-catalyzed $\mathrm{C}-\mathrm{H} / \mathrm{C}-\mathrm{X}$ biaryl coupling.

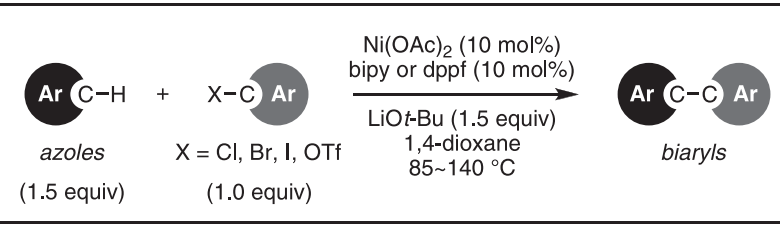

Scope of Azoles (with iodobenzene): Ni(OAC) $2 /$ bipy $/ 85{ }^{\circ} \mathrm{C}$

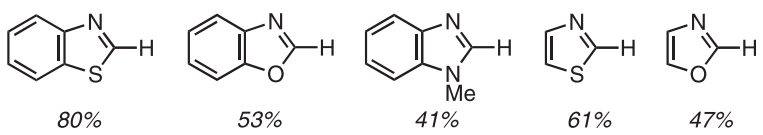

Scope of $\mathrm{ArBr}$ and $\mathrm{Arl}$ (with benzothiazole): $\mathrm{Ni}(\mathrm{OAC})_{2} / \mathrm{bipy} / 85{ }^{\circ} \mathrm{C}$

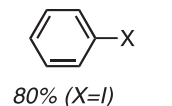

$80 \%(X=I)$

$51 \%(X=l, 1 \% \mathrm{Ni})$ $62 \%(X=B r)$<smiles>[R]c1ccc(I)cc1</smiles><smiles>[X]c1ccccc1C</smiles>
$\mathrm{Me}$ $90 \%(X=I)$
$82 \%(X=B r)$<smiles>[X]c1cccc(C)c1</smiles>
$71 \%(X=I)$ $63 \%(X=B r)$

$\mathrm{R}$ (yield):

$\mathrm{MeO}(65 \%), \mathrm{Cl}(51 \%), \mathrm{CN}(78 \%), \mathrm{CF}_{3}(68 \%)$<smiles>COc1cc(Br)cc(OC)c1OC</smiles><smiles>Ic1cccnc1</smiles>

$57 \%$<smiles>Ic1ccccc1-c1ccccc1</smiles><smiles>Ic1ccsc1</smiles>

$74 \%$

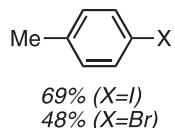

$69 \%(X=I)$
$48 \%(X=B r)$
Scope of $\mathrm{ArCl}$ and ArOTf (with benzothiazole): $\mathrm{Ni}(\mathrm{OAC})_{2} / \mathrm{dppf} / 140{ }^{\circ} \mathrm{C}$

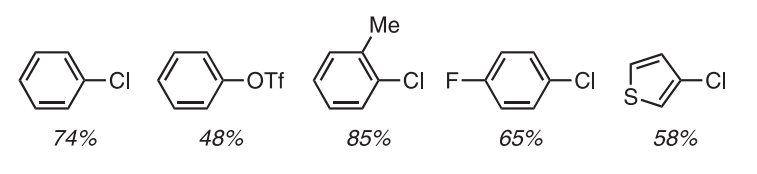

Scheme 8. Rapid synthesis of febuxostat.

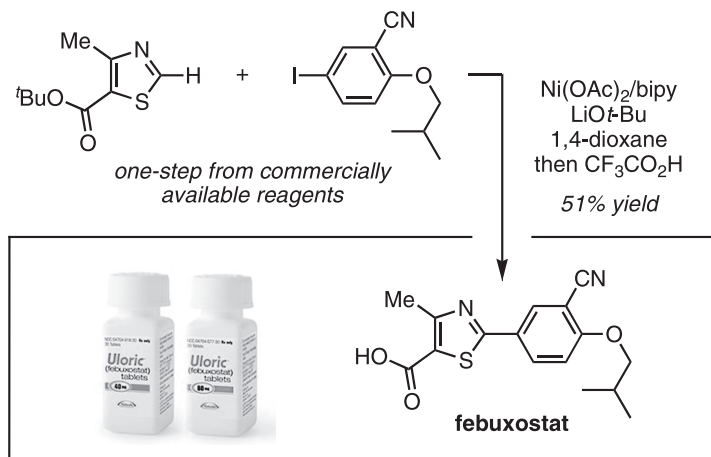

Emerging drug for gout and hyperuricemia (Teijin Pharma) Novel, nonpurine, selective inhibitor of xanthine oxidase Approved in Europe (2008), USA (2009), and others 1 Billion USD/year (expected), 50 100 ton/year (expected) 
selective inhibitor of xanthine oxidase, which is effective for the treatment of gout and hyperuricemia. ${ }^{18}$ Under the influence of the $\mathrm{Ni}(\mathrm{OAc})_{2} /$ bipy catalyst and $\mathrm{LiO} t-\mathrm{Bu}$, the thiazole derivative and iodobezene derivative underwent $\mathrm{C}-\mathrm{H} / \mathrm{C}-\mathrm{X}$ biaryl coupling in 1,4 -dioxane at $100{ }^{\circ} \mathrm{C}$, furnishing the corresponding arylated thiazole. Subsequent treatment with $\mathrm{CF}_{3} \mathrm{CO}_{2} \mathrm{H}$ afforded febuxostat in $51 \%$ overall yield. The synthesis is extremely efficient, as both of the coupling components can be quickly derived in one-step from commercially available 4-methyl-5-thiazolecarboxylic acid and 2-fluoro-5iodobenzonitrile, respectively. ${ }^{15}$

\section{Potassium $t$-Butoxide Mediated $\mathrm{C}-\mathrm{H} / \mathrm{C}-\mathrm{X}$ Biaryl Coupling}

The direct $\mathrm{C}-\mathrm{H}$ bond arylation of electron-deficient nitrogen heterocycles such as pyridine has been a problematic reaction in this field. ${ }^{19}$ Indeed, none of our catalysts described above are active for these substrates. Therefore, the development of a $\mathrm{C}-\mathrm{H}$ bond arylation protocol applicable to sixmembered nitrogen heterocycles became our next goal.

Initially, we hypothesized that a "radical-type" transition metal mediated reaction might be optimal for achieving such a process. ${ }^{20}$ Thus, we examined Fujita's Ir-based protocol, ${ }^{12}$ which has been assumed to be a radical process, for the coupling of pyridine and iodobenzene. In fact, the $\mathrm{C}-\mathrm{H}$ bond phenylation of pyridine with iodobenzene was affected in the presence of $\left[\mathrm{Cp}^{*} \mathrm{IrHCl}\right]_{2}$ and $\mathrm{KO} t-\mathrm{Bu}$ to give phenylpyridine as a mixture of regioisomers. We also found that a variety of Ir sources were apparently able to catalyze this reaction in moderate yield. Struck by the similarity of reactions employing dramatically distinct Ir sources, we carried out the coupling reaction in the absence of Ir and remarkably found that the coupling reaction proceeded to the same extent with $\mathrm{KO} t-\mathrm{Bu}$ as the sole reagent. ${ }^{21}$

With these unexpected results in hand, we further examined the reaction conditions using pyrazine as a substrate (Scheme 9). ${ }^{21}$ When a mixture of pyrazine (40 equiv), iodobenzene (1.0 equiv), and $\mathrm{KO} t-\mathrm{Bu}$ (1.5 equiv) was stirred in the dark at $120^{\circ} \mathrm{C}$ for $13 \mathrm{~h}, \mathrm{C}-\mathrm{H}$ bond phenylation took place to afford 2-phenylpyrazine in $79 \%$ yield. Under microwave irradiation, a quantitative coupling occurred after $5 \mathrm{~min}$ at $50{ }^{\circ} \mathrm{C} .{ }^{22}$ The same reaction also took place using bromobenzene at $80{ }^{\circ} \mathrm{C}(54 \%)$, but chlorobenzene and fluorobenzene were virtually unreactive under these conditions. Interestingly, the use of $N, N$-dimethylacetamide (DMAc) as solvent allowed the reaction to proceed at room temperature, albeit less efficiently. Other potential promoters related to $\mathrm{KO} t-\mathrm{Bu}$ were also examined. The use of $\mathrm{NaO} t-\mathrm{Bu}$ or $\mathrm{LiO} t-\mathrm{Bu}$ instead of $\mathrm{KO} t-\mathrm{Bu}$ did not afford the product at $50{ }^{\circ} \mathrm{C}$. However, at temperatures above $80{ }^{\circ} \mathrm{C}, \mathrm{NaO} t-\mathrm{Bu}$ also promoted the biaryl coupling. In addition to the nature of the metal cation $(\mathrm{K})$, the $t$-butoxide

Scheme 9. Discovery of the $\mathrm{KO} t-\mathrm{Bu}$-promoted $\mathrm{C}-\mathrm{H} / \mathrm{C}-\mathrm{X}$ biaryl coupling.

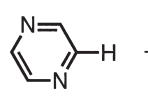

(40 equiv)

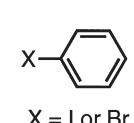

(1.0 equiv)
$\mathrm{KO}$-Bu

(1.5 equiv)

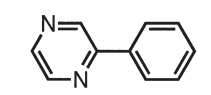

$79 \%\left(X=1 ; 1200^{\circ} \mathrm{C}, 13 \mathrm{~h}\right)$ $98 \%\left(X=l ; 50^{\circ} \mathrm{C}, 5 \mathrm{~min}, \mu \mathrm{W}\right)$ $54 \%\left(X=B r ; 80^{\circ} \mathrm{C}, 30 \mathrm{~min}, \mu \mathrm{W}\right)$
Rxn proceeds even at it when using DMAc as a solvent Ineffective with $\mathrm{NaOt}-\mathrm{Bu}$, LiOt-Bu, $\mathrm{KOMe}, \mathrm{KOH}$ moiety is also crucial, as $\mathrm{KOMe}$ and $\mathrm{KOH}$ exhibited almost no reactivity.

Next the scope of the reaction with respect to the haloarene and nitrogen heterocycle was examined. Representative results are summarized in Scheme 10. Various iodoarenes and bromoarenes reacted with pyrazine to give the corresponding nitrogen-containing biaryls in good yields. These reactions took place exclusively at the $\mathrm{C}-\mathrm{X}$ bond of haloarenes, and regioisomers with respect to the haloarene were not detected. These results imply that our reaction does not proceed through aryne intermediates. Other than haloarenes, haloalkenes such as $\beta$-iodostyrene also reacted with pyrazine. A range of electron-deficient nitrogen heterocycles other than pyrazine underwent arylation with haloarenes. For example, pyridine, pyridazine, pyrimidine, and quinoxaline reacted with iodobenzene to afford the coupling products in good yields, albeit with poor regioselectivity with respect to the heterocycle.

Scheme 10. $\mathrm{KO} t-\mathrm{Bu}$-promoted arylation of $\mathrm{N}$-heterocycles.

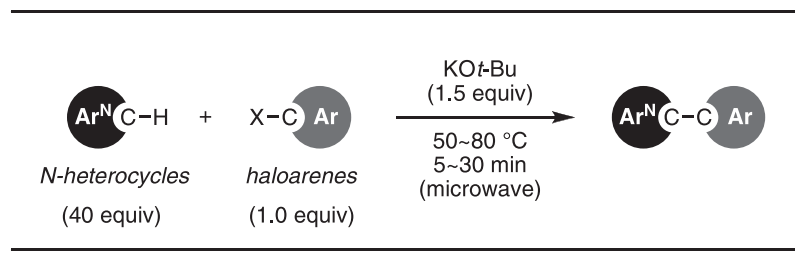

Scope of Haloarenes (with pyrazine)
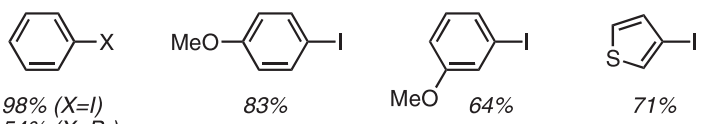

$54 \%(X=B r)$

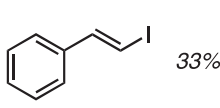

Scope of $\mathrm{N}$-Heterocycles (with iodobenzene)

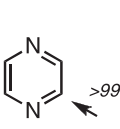

$98 \%$<smiles>Cc1ccnc(C)c1C</smiles>

$63 \%$

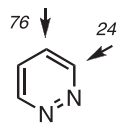

$56 \%$

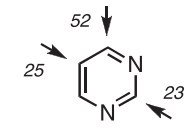

$59 \%$

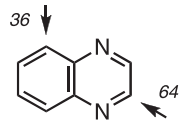

$75 \%$
Considering that trace transition metals present in basic additives have been shown in some cases to catalyze coupling reactions such as the Suzuki-Miyaura reaction when performed under forcing conditions, ${ }^{23}$ all reagents were purified extensively before use, including sublimation for $\mathrm{KO} t-\mathrm{Bu}$. All reaction glassware and equipment were thoroughly cleaned prior to use. Finally, a quantitative elemental analysis of $\mathrm{KO} t-$ $\mathrm{Bu}$ was conducted by ICP-AES (Inductively Coupled PlasmaAtomic Emission Spectrometry). ${ }^{21}$ Though very low in concentration, the most abundant exogenous elements found to be present in the $\mathrm{KO} t-\mathrm{Bu}$ used in this study were $\mathrm{Si}(0.92 \mathrm{ppm})$, $\mathrm{Al}(0.38 \mathrm{ppm})$, and $\mathrm{Ca}(0.048 \mathrm{ppm})$. More importantly, no transition metal was present at over $0.50 \mathrm{ppm}$ in the $\mathrm{KO} t-\mathrm{Bu}$ employed in our study. In particular, $\mathrm{Pd}, \mathrm{Rh}$, and $\mathrm{Ru}$, which 
one might suspect as potential catalysts for such biaryl couplings, were present if at all at concentrations below their detection limits (Pd: $<0.06$ ppm, Rh: $<0.20$ ppm, Ru: $<0.30$ $\mathrm{ppm})$. Although the possibility of transition metal mediation in this reaction cannot be completely excluded, such a catalyst, if any, must be effective at low ppb concentrations.

Several control experiments indicated that the present biaryl coupling involves the $\mathrm{KO} t-\mathrm{Bu}$-induced generation of an aryl radical from the haloarene (SET then $\mathrm{C}-\mathrm{X}$ bond cleavage), followed by homolytic aromatic substitution or $\mathrm{S}_{\mathrm{RN}} 1$ reaction (Scheme 11). The importance of a potassiumnitrogen interaction has been also suggested by several control experiments. ${ }^{24}$ While other mechanisms cannot be rigorously excluded, the radical nature of the present reaction was supported by control experiments performed in the presence of radical scavengers (Scheme 11). ${ }^{21}$ For example, the addition of 2,2,6,6-tetramethylpiperidine 1-oxyl (TEMPO), galvinoxyl, or acrylonitrile to the reaction of pyrazine, iodobenzene, and $\mathrm{KO} t-\mathrm{Bu}$ completely shut down the otherwise efficient biaryl coupling. Furthermore, we observed the formation of 2-cyclohexylpyrazine when the reaction was conducted in the presence of cyclohexane (Scheme 11). ${ }^{24}$ This reaction most likely proceeds through the cyclohexyl radical, generated by the radical exchange reaction of phenyl radical and cyclohexane.

Scheme 11. Radical nature of the $\mathrm{KO} t-\mathrm{Bu}$-promoted biaryl coupling.

\section{A Possible Mechanism}<smiles></smiles>
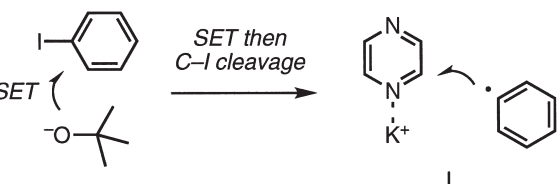<smiles>c1ccc(-c2cnccn2)cc1</smiles>

addition/elimination

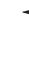

Radical Scavenging/Trapping Experiments

Reaction with galvinoxyl, TEMPO, or acrylonitrile (1 equiv)

$\Rightarrow$ No coupling products ( $<1 \%$ yield)

Reaction with cyclohexane (40 equiv)

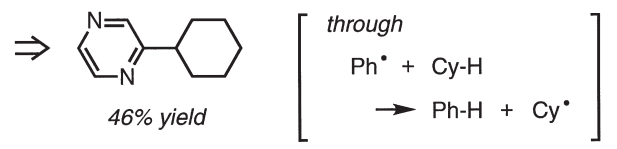

\section{Copper-Mediated C-H/C-B Biaryl Coupling}

The metalation of a $\mathrm{C}-\mathrm{H}$ bond is a key step in the $\mathrm{C}-\mathrm{H}$ bond arylation of aromatic compounds. Our basic strategy has been to establish a distinct nucleophile-electrophile interaction between an arene and a transition metal, thereby promoting electrophilic arene metalation. As an alternative to using electron-withdrawing neutral ligands such as $\mathrm{P}\left[\mathrm{OCH}\left(\mathrm{CF}_{3}\right)_{2}\right]_{3}$ for $\mathrm{C}-\mathrm{H} / \mathrm{C}-\mathrm{X}$ biaryl coupling, we surmised that the use of an electron-withdrawing anionic ligand would facilitate the oxidative biaryl coupling of arenes and arylboronic acids (C$\mathrm{H} / \mathrm{C}-\mathrm{B}$ biaryl coupling) as shown in Scheme $12 .{ }^{25}$

After an extensive screening of metal salts based on such a
Scheme 12. Initial strategy for $\mathrm{C}-\mathrm{H} / \mathrm{C}-\mathrm{B}$ biaryl coupling.

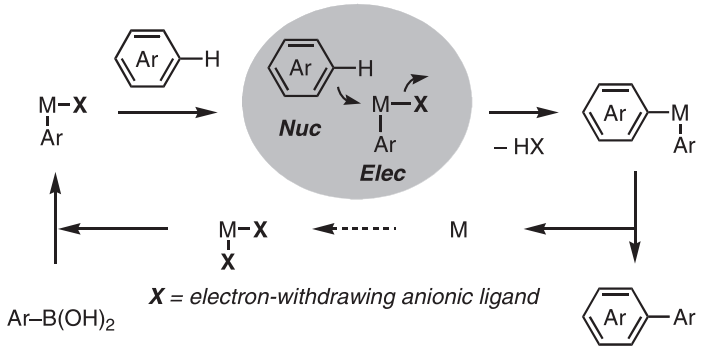

scenario, we found that $\mathrm{Cu}\left(\mathrm{OCOCF}_{3}\right)_{2}$ promotes the $\mathrm{C}-\mathrm{H} / \mathrm{C}-$ $\mathrm{B}$ biaryl coupling of electron-rich arenes and arylboronic acids (Scheme 13). ${ }^{25}$ As a typical example, when a mixture of 1,3,5-trimethoxybenzene (1.0 equiv) and phenylboronic acid (2.0 equiv) was treated with $\mathrm{Cu}\left(\mathrm{OCOCF}_{3}\right)_{2}$ (1.0 equiv) and $\mathrm{CF}_{3} \mathrm{CO}_{2} \mathrm{H}$ (1.0 equiv) in 1,2 -dichloroethane at $80{ }^{\circ} \mathrm{C}$ for $13 \mathrm{~h}$ under air, the cross-coupling product was obtained in $68 \%$ yield. Surprisingly, the reaction was selective for crosscoupling; no homocoupled product arising from either 1,3,5trimethoxybenzene or phenylboronic acid was detected. The importance of the trifluoroacetate moiety was quickly recognized, as other $\mathrm{Cu}(\mathrm{II})$ salts such as $\mathrm{Cu}\left(\mathrm{OCOCH}_{3}\right)_{2}, \mathrm{Cu}(\mathrm{OTf})_{2}$, and $\mathrm{CuCl}_{2}$ did not promote the reaction at all. The reaction under argon atmosphere was significantly slower than that performed under air. Reducing the amount of copper $(0.3$ equiv) resulted in a $45 \%$ yield; under current conditions the reaction is limited by low TON (turnover number) with respect to copper.

Scheme 13. $\mathrm{Cu}\left(\mathrm{OCOCF}_{3}\right)_{2}-$ mediated $\mathrm{C}-\mathrm{H} / \mathrm{C}-\mathrm{B}$ biaryl coupling.

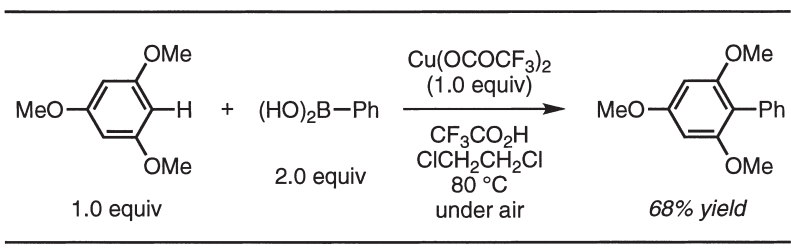

Selective for cross-coupling
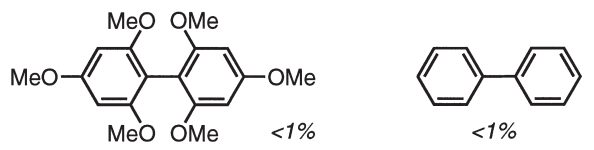

No coupling with $\mathrm{Cu}(\mathrm{OAC})_{2}, \mathrm{Cu}(\mathrm{OTf})_{2}$, or $\mathrm{CuCl}_{2}$

Promoting effects of $\mathrm{CF}_{3} \mathrm{CO}_{2} \mathrm{H}$ and air

Applicable to a range of arylboronic acids
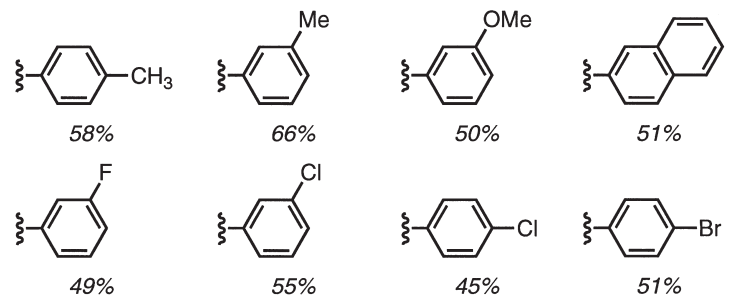

More interestingly, multiple $\mathrm{C}-\mathrm{H}$ bond arylation is possible with some nitrogen heterocycles (Scheme 14). For example, when $N$-methylindole (1.0 equiv) was reacted with $\mathrm{PhB}(\mathrm{OH})_{2}$ (3.0 equiv) under the influence of $\mathrm{Cu}\left(\mathrm{OCOCF}_{3}\right)_{2}$, double phenylation took place. When $N$-methylpyrrole (1.0 equiv) was reacted with $\mathrm{PhB}(\mathrm{OH})_{2}$ (5.9 equiv), quadruple phenylation 
took place to afford tetraphenylpyrrole in 51\% yield. It should be noted that the tetraarylpyrrole motif is a target of interest, present in materials for organic electroluminescence devices ${ }^{26}$ and in an antioxidant inhibiting microsomal lipid oxidation. ${ }^{27}$ Also worthy of note is that such a facile multiple $\mathrm{C}-\mathrm{H}$ bond arylation does not take place in the seemingly related $\mathrm{Pd}$-catalyzed oxidative arene cross-coupling reactions. ${ }^{28,29}$ These results, together with a quantitative elemental analysis of $\mathrm{Cu}\left(\mathrm{OCOCF}_{3}\right)_{2}$ by ICP-AES showing that the Pd concentration is less than $0.40 \mathrm{ppm}$ (detection limit), imply that the present reaction is not likely to be mediated by trace palladium.

Scheme 14. Multiple $\mathrm{C}-\mathrm{H}$ bond arylation of $\mathrm{N}$-heterocycles.
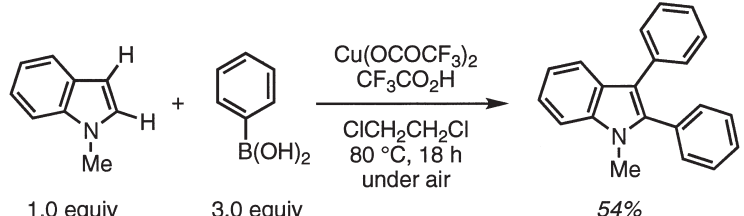

1.0 equiv
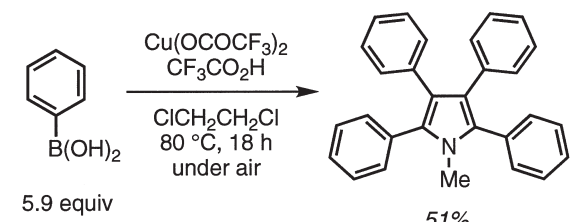

\section{Programmed Synthesis of Tetraarylthiophenes: Regioselec} tive Multiple C-H Arylations of Thiophenes

As already stated in Section 2, multiply arylated heterocycles are privileged structures with many interesting functions. In order to accelerate the discovery of new functional molecules of this class, a flexible method for accessing all possible isomers in a programmable manner is much needed. After extensive catalyst-development studies aimed ultimately at establishing a programmed synthesis of multiply arylated heterocycles using $\mathrm{C}-\mathrm{H}$ bond arylation technology, a general protocol for the programmed synthesis of tetraarylthiophenes was developed. ${ }^{30}$ The development of regioselective $\mathrm{C}-\mathrm{H}$ bond arylation catalysts has been a key to realizing our concept.

Prior to catalyst development, we had designed a basic structure of starting material (thiophene derivative) suitable for the programmed synthesis of tetraarylthiophenes (Scheme 15). Although thiophene itself is the most straightforward starting material, achieving complete regioselectivity in $\mathrm{C}-\mathrm{H}$ bond arylations might be difficult due to its symmetrical

Scheme 15. General strategy for the programmed synthesis of tetraarylthiophenes.
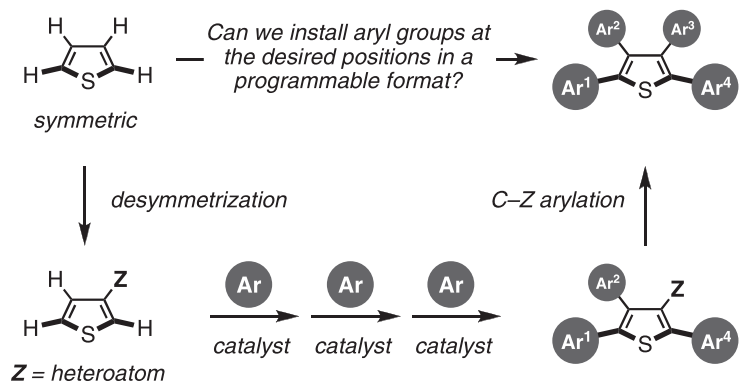

Bond-selective and sequential $\mathrm{C}-\mathrm{H}$ bond arylations structure (existence of two sets of chemically equivalent $\mathrm{C}-\mathrm{H}$ bonds). Thus, we decided to replace one of the hydrogen atoms on thiophene with a permutable heteroatom that can be transformed to an aryl group afterwards. ${ }^{5 b}$ Such desymmetrization of the thiophene ring (reactivity differentiation of thienyl $\mathrm{C}-\mathrm{H}$ bonds) would in principle allow bond-selective sequential arylations of the thiophene core, realizing a programmed synthesis of tetraarylthiophenes. ${ }^{3,5}$ Though conceptually intriguing, such an approach has remained relatively unexplored due to the difficulty in activating three thienyl $\mathrm{C}-\mathrm{H}$ bonds toward catalytic $\mathrm{C}-\mathrm{H}$ arylation reactions, and/or in controlling regioselectivity. ${ }^{31}$

We selected 3-methoxythiophene (3) as our first-generation platform ${ }^{5 b}$ for tetraarylthiophene synthesis because of its high reactivity and selectivity in the catalytic $\mathrm{C}-\mathrm{H}$ bond arylation with iodoarenes. ${ }^{8,13}$ For example, 3 reacts with iodobenzene in the presence of $\mathrm{RhCl}(\mathrm{CO})\left\{\mathrm{P}\left[\mathrm{OCH}\left(\mathrm{CF}_{3}\right)_{2}\right]_{3}\right\}_{2}$ catalyst (1) and $\mathrm{Ag}_{2} \mathrm{CO}_{3}$ producing 3-methoxy-2-phenylthiophene (4a) in $80 \%$ yield with virtually complete regioselectivity. ${ }^{8}$ This C2-selective arylation occurs with various iodoarenes. ${ }^{8}$ Thus, the focal point of this study has been to establish a C4-and/or C5-selective catalyst for the arylation of 2-aryl-3-methoxythiophenes $\mathbf{4}$. However, we found that use of Rh catalyst $\mathbf{1}$ is problematic for further arylations. For example, the reaction of $\mathbf{4 a}$ and iodobenzene in the presence of $\mathbf{1}$ and $\mathrm{Ag}_{2} \mathrm{CO}_{3}$ furnished the $\mathrm{C} 5$ phenylation product $\mathbf{5 a}$ in only $38 \%$ yield. Even more critically, further arylation (C4 arylation) did not take place with $\mathbf{1}$. Thus, the need for a new catalytic system was obvious at this point. In particular, the development of a catalyst promoting the hard-to-achieve arylation at the $\beta$-position of the thiophene ring was crucial. ${ }^{32}$

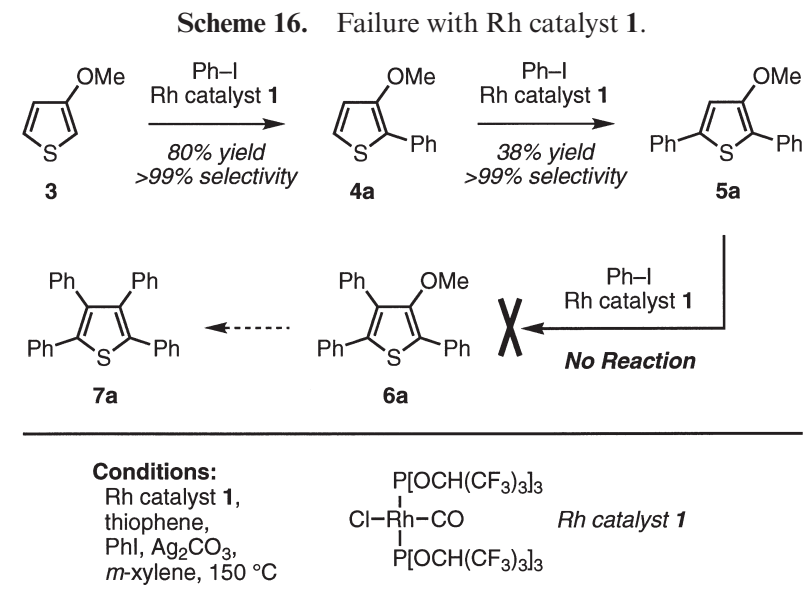

Extensive screening led to the development of two new Pd catalysts (Cat-A and Cat-B) for the second and third arylations of 3, respectively (Scheme 17). ${ }^{30}$ We first found that the otherwise difficult $\mathrm{C} 4$-selective arylation of $\mathbf{4 a}$ with iodoarenes can be promoted by the catalyst $\mathrm{PdCl} / 2 \mathrm{P}\left[\mathrm{OCH}\left(\mathrm{CF}_{3}\right)_{2}\right]_{3}$ (CatA) and $\mathrm{Ag}_{2} \mathrm{CO}_{3}$ in $m$-xylene at $120{ }^{\circ} \mathrm{C}$, furnishing 8 with high regioselectivity $(93-98 \% \mathrm{C} 4)$. Given the C5 selectivity of $\mathrm{Rh} / \mathrm{P}\left[\mathrm{OCH}\left(\mathrm{CF}_{3}\right)_{2}\right]_{3}$ catalyst $\mathbf{1}$ for the arylation of $\mathbf{4 a}$ (Scheme 16), an interesting metal-controlled regiodivergency (C5 for $\mathrm{Rh}, \mathrm{C} 4$ for $\mathrm{Pd}$ ) has been identified for $\mathrm{P}\left[\mathrm{OCH}\left(\mathrm{CF}_{3}\right)_{2}\right]_{3}-$ bound metal catalysts. More interestingly, we found that the $\mathrm{C} 4 \mathrm{selec}-$ tivity of Cat-A can be switched to C5 selectivity ( 98 to $>99 \%$ ) by changing the supporting neutral ligand to 2,2 '- bipyridy $^{33}$ 
(Cat-B). This ligand-controlled regiodivergent $\mathrm{C}-\mathrm{H}$ arylation (C4 for $\mathrm{P}\left[\mathrm{OCH}\left(\mathrm{CF}_{3}\right)_{2}\right]_{3}, \mathrm{C} 5$ for 2,2'-bipyridyl) turned out to be general for $\mathrm{PdCl}_{2} / \mathrm{Ag}_{2} \mathrm{CO}_{3}$ catalysis (Scheme 17). ${ }^{30}$

Scheme 17. Discovery of regiodivergent $\mathrm{C}-\mathrm{H}$ bond arylation catalysts.

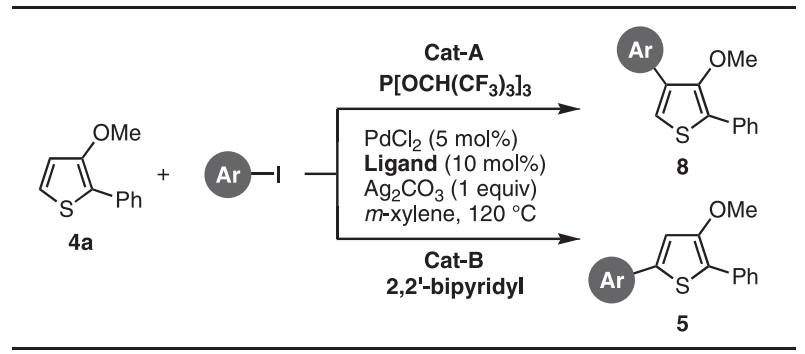

Regioselectivities (8:5) are shown. Yields are 69 98\%.

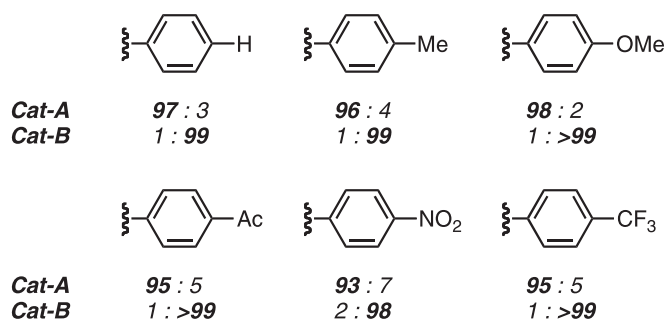

With two regiodivergent $\mathrm{C}-\mathrm{H}$ arylation catalysts in hand, the third $\mathrm{C}-\mathrm{H}$ arylation for making 2,4,5-triaryl-3-methoxythiophenes 6 was next examined for two possible routes, one

Scheme 18. General synthetic scheme for tetraarylthiophenes.

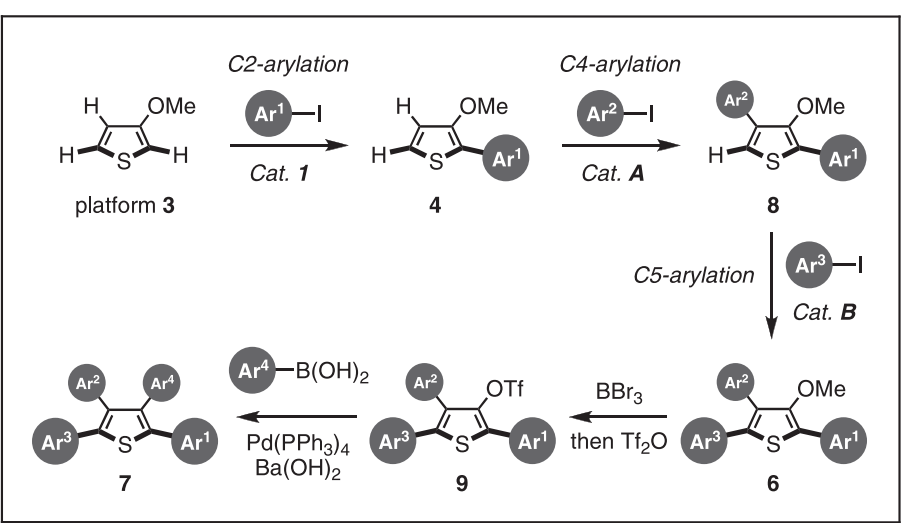

Representative tetraarylthiophenes 7 synthesized<smiles>COc1ccc(-c2c(-c3ccccc3)sc(-c3ccc(C(F)(F)F)cc3)c2-c2ccc(C)cc2)cc1</smiles><smiles>Cc1ccc(-c2c(-c3ccc(Cl)cc3)sc(-c3ccccc3)c2-c2ccc(C(F)(F)F)cc2)cc1</smiles><smiles>COc1ccc(-c2c(-c3ccccc3)sc(-c3ccc(C)cc3)c2-c2ccc(C(F)(F)F)cc2)cc1</smiles><smiles>Cc1ccc(-c2sc(-c3ccccc3)c(-c3ccc(Cl)cc3)c2-c2ccc(C(F)(F)F)cc2)cc1</smiles>

via 8, the other via 5 (Scheme 18). Gratifyingly, the Cat-B system promoted the C5 arylation of 2,4-diaryl-3-methoxythiophenes $\mathbf{8}$ with iodoarenes, giving $\mathbf{6}$ in good yields. Under otherwise identical conditions, the Cat-A system was unable to promote the $\mathrm{C}-\mathrm{H}$ bond arylation of $\mathbf{5}$.

Finally, the fourth arylation to obtain the targeted tetraarylthiophenes 7 was investigated. Extensive screening of reaction conditions established a high-yielding procedure involving Suzuki-Miyaura coupling (Scheme 18). Thus, the $\mathrm{BBr}_{3}$-promoted demethylation of $\mathbf{6}$ followed by treatment of the thus-obtained crude alcohols with $\mathrm{Tf}_{2} \mathrm{O} / i-\mathrm{Pr}_{2} \mathrm{NEt} / \mathrm{DMAP}$ produced the corresponding triflates 9 in high yields $(>70 \%)$. The triflates 9 were cross-coupled with arylboronic acids in the presence of $\mathrm{Pd}\left(\mathrm{PPh}_{3}\right)_{4}$ catalyst and $\mathrm{Ba}(\mathrm{OH})_{2}$ to finally afford tetraarylthiophenes 7 in good yields with virtually complete isomeric purities. $^{34}$

Noteworthy features of the present method are that (i) all of the aryl groups assembled on the thiophene core are derived from readily available aryl iodides or boronic acids, (ii) the installation of aryl groups at the desired position can be achieved, and (iii) simple alteration of the order in which the aryl reagents are used in the sequence results in the selective production of all possible isomers of tetraarylthiophenes. Although we focused on the synthesis of tetraarylthiophenes, our strategy should also be applicable to the regioselective synthesis of di- or triarylated thiophenes by skipping one or two of the $\mathrm{C}-\mathrm{H}$ arylation steps prior to the final $\mathrm{C}-\mathrm{O}$ bond arylation. The present strategy should find many uses for combinatorial lead-structure identification and optimization in the development of functional organic materials for which the structure-property relationships are often not easily predictable.

\section{Summary}

In this account, we have described the early stages of our campaign toward the realization of ideal arene assembly through catalytic $\mathrm{C}-\mathrm{H}$ bond arylation of aromatic compounds. Among the various discoveries and phenomena found during this endeavor, (i) the introduction of the extremely electronwithdrawing $\mathrm{P}\left[\mathrm{OCH}\left(\mathrm{CF}_{3}\right)_{2}\right]_{3}$ ligand in $\mathrm{C}-\mathrm{H}$ bond functionalization, (ii) the discovery of nickel catalysis of $\mathrm{C}-\mathrm{H}$ bond arylation, (iii) the metal- and ligand-controlled regiodivergency in aromatic functionalization, and (iv) the serendipitous discovery of $t$-butoxide-mediated biaryl coupling are particularly noteworthy. Although we have focused much of our efforts over the last four years on acquiring an efficient and unique catalyst toolbox, currently we are paying significant attention to the synthesis of biofunctional substances (drugs, drug-like compounds, and natural products), and functional organic materials using $\mathrm{C}-\mathrm{H}$ bond functionalization chemistry to embark on more challenging quests in chemical science. We hope that this enterprise will not only streamline the state-ofthe-art synthesis of useful molecular entities, but also contribute to changing the way chemists plan syntheses.

\section{Acknowledgement}

The author would like to express his sincere appreciation to all the present and past members of his research group at Nagoya University for their invaluable contributions. The author thanks Prof. Atsushi Wakamiya (Kyoto University) for assistance with $\mathrm{X}$-ray crystal structure analysis. The Japan 
Society for the Promotion of Science (JSPS) is gratefully acknowledged for postdoctoral fellowships (Jean Bouffard, Benoît Join, and Jérôme Canivet) and predoctoral fellowships (Shuichi Yanagisawa, Masakazu Nambo, Haruka Omachi, and Kirika Ueda). This work was supported in part by Grantsin-Aid for Scientific Research from the Ministry of Education, Culture, Sports, Science and Technology (MEXT), Japan, the PRESTO program of the Japan Science and Technology Agency, the Kurata Memorial Hitachi Science and Technology Foundation, and the Asahi Glass Foundation. The Nagoya University Global COE Program in Chemistry and the MEXT Joint Project of Chemical Synthesis Core Research Institutions are also acknowledged for support.

\section{References}

1) Hassan, J.; Sévignon, M.; Gozzi, C.; Schulz, E.; Lemaire, M. Chem. Rev. 2002, 102, 1359.

2) An excellent recent review: Ackermann, L.; Vincente, R.; Kapdi, A. R. Angew. Chem. Int. Ed. 2009, 48, 9792.

3) Early important works in this field: (a) Nakamura, N.; Tajima, Y.; Sakai, K. Heterocycles 1982, 17, 235. (b) Akita, Y.; Itagaki, Y.; Takizawa, S.; Ohta, A. Chem. Pharm. Bull. 1989, 37, 1477. (c) Ohta, A.; Akita, Y.; Ohkuwa, T.; Chiba, M.; Fukunaga, R.; Miyafuji, A.; Nakata, T.; Tani, N.; Aoyagi, Y. Heterocycles 1990, 31, 1951. (d) Pivsa-Art, S.; Satoh, T.; Kawamura, Y.; Miura, M.; Nomura, M. Bull. Chem. Soc. Jpn. 1998, 71, 467.

4) Reviews on transition metal-catalyzed $\mathrm{C}-\mathrm{C}$ bond formation via $\mathrm{C}-\mathrm{H}$ bond cleavage: (a) Kakiuchi, F.; Kochi, T. Synthesis 2008, 3013. (b) Kakiuchi, F.; Chatani, N. Adv. Synth. Catal. 2003, 345, 1077.

5) (a) Itami, K.; Yamazaki, D.; Yoshida, J. J. Am. Chem. Soc. 2004, 126, 15396. (b) Itami, K.; Yoshida, J. Chem. Eur. J. 2006, 12, 3966.

6) Okazawa, T.; Satoh, T.; Miura, M.; Nomura, M. J. Am. Chem. Soc. 2002, 124, 5286.

7) Itami, K.; Usutani, H.; Yoshida, J. unpublished results.

8) (a) Yanagisawa, S.; Sudo, T.; Noyori, R.; Itami, K. J. Am. Chem. Soc. 2006, 128, 11748. (b) Yanagisawa, S.; Sudo, T.; Noyori, R.; Itami, K. Tetrahedron 2008, 64, 6073. (c) Omachi, H.; Itami, K. Chem. Lett. 2009, 38,186

9) (a) van Leeuwen, P. W. N. M.; Roobeek, C. F. Tetrahedron 1981, 37, 1973. (b) Jolly, R. S.; Ludtke, G.; Sheehan, D.; Livinghouse, T. J. Am. Chem. Soc. 1990, 112, 4965. (c) Wender, P. A.; Jenkins, T. E.; Suzuki, S. J. Am. Chem. Soc. 1995, 117, 1843. (d) Murakami, M.; Ubukata, M.; Itami, K.; Ito, Y. Angew. Chem. Int. Ed. 1998, 37, 2248.

10) A review on $\mathrm{Rh}$-catalyzed $\mathrm{C}-\mathrm{H}$ bond arylation of arenes: (a) Bouffard, J.; Itami, K. Top. Curr. Chem. 2010, 292, 231. Selected other examples of $\mathrm{Rh}$-catalyzed $\mathrm{C}-\mathrm{H} / \mathrm{C}-\mathrm{X}$ biaryl coupling: (b) Bedford, $\mathrm{R}$. B.; Coles, S. J.; Hursthouse, M. B.; Limmert, M. E. Angew. Chem. Int. Ed. 2003, 42, 112. (c) Oi, S.; Watanabe, S.; Fukita, S.; Inoue, Y. Tetrahedron Lett. 2003, 44, 8665. (d) Wang, X.; Lane, B. S.; Sames, D. J. Am. Chem. Soc. 2005, 127, 4996. (e) Proch, S.; Kempe, R. Angew. Chem. Int. Ed. 2007, 46, 3135. (f) Lewis, J. C.; Bergman, R. G.; Ellman, J. A. Acc. Chem. Res. 2008, 41, 1013.

11) Tolman, C. A. Chem. Rev. 1977, 77, 313.

12) A sole example using $\mathrm{Ir}$ catalysts for $\mathrm{C}-\mathrm{H}$ bond arylation of arenes (benzene derivatives) with iodoarenes: Fujita, K.; Nonogawa, M.; Yamaguchi, R. Chem. Commun. 2004, 1926.

13) Join, B.; Yamamoto, T.; Itami, K. Angew. Chem. Int. Ed. 2009, 48, 3644 .

14) (a) Crabtree, R. H. Acc. Chem. Res. 1979, 12, 331. (b) Crabtree, R. H.; Davis, M. W. J. Org. Chem. 1986, 51, 2655.

15) Canivet, J.; Yamaguchi, J.; Ban, I.; Itami, K. Org. Lett. 2009, 11, 1733.

16) Other $\mathrm{Ni}$-catalyzed $\mathrm{C}-\mathrm{H} / \mathrm{C}-\mathrm{X}$ biaryl coupling: (a) Hachiya, H.; Hirano, K.; Satoh, T.; Miura, M. Org. Lett. 2009, 11, 1737. (b) Kobayashi, O.; Uraguchi, D.; Yamakawa, T. Org. Lett. 2009, 11, 2679.

17) The price of representative catalyst precursors in arene arylation (Strem Chemicals, Inc.): $\mathrm{Ni}(\mathrm{OAc})_{2} \cdot 4 \mathrm{H}_{2} \mathrm{O}(\$ 126$ for $1 \mathrm{~kg}), \mathrm{CuI}(\$ 102$ for $500 \mathrm{~g}),\left[\mathrm{RuCl}_{2}(p \text {-cymene) }]_{2}\right.$ (\$116 for $5 \mathrm{~g}$ ), $\mathrm{Pd}(\mathrm{OAc})_{2}$ (\$678 for 25 $\mathrm{g}),\left[\mathrm{RhCl}(\mathrm{CO})_{2}\right]_{2}(\$ 610$ for $2 \mathrm{~g})$.

18) Synthesis: (a) Watanabe, K.; Tanaka, T.; Kondo, S. Jpn. Kokai Tokkyo Koho 1994, 329647. Treatment study and mechanism: (b) Becker, M. A.; Schumacher, H. R. Jr.; Wortmann, R. L.; MacDonald, P. A.; Eustace, D.; Palo, W. A.; Streit, J.; Joseph-Ridge, N. New Engl. J. Med. 2005, 353, 2450. (c) Okamoto, K.; Eger, B. T.; Nishino,
T.; Kondo, S.; Pai, E. F.; Nishino, T. J. Biol. Chem. 2003, $278,1848$.

19) (a) Mukhopadhyay, S.; Rothenberg, G.; Gitis, D.; Baidossi, M.; Ponde, D. E.; Sasson, Y. J. Chem. Soc., Perkin Trans. 2 2000, 1809. (b) Campeau, L.-C.; Rousseaux, S.; Fagnou, K. J. Am. Chem. Soc. 2005, 127, 18020. (c) Leclerc, J.-P.; Fagnou, K. Angew. Chem. Int. Ed. 2006, 45, 7781. (d) Cho, S. H.; Hwang, S. J.; Chang, S. J. Am. Chem. Soc. 2008, 130, 9254. (e) Berman, A. M.; Lewis, J. C.; Bergman, R. G.; Ellman, J. A. J. Am. Chem. Soc. 2008, 130, 14926. (f) Tobisu, M.; Hyodo, I.; Chatani, N. J. Am. Chem. Soc. 2009, 131, 12070.

20) (a) Möhlau, R.; Berger, R. Chem. Ber. 1893, 26, 1994. (b) Gomberg, M.; Bachmann, W. E. J. Am. Chem. Soc. 1924, 46, 2339. (c) Hey, D. H.; Walker, E. W. J. Chem. Soc. 1948, 2213. (d) Fields, E. K.; Meyerson, S. J. Org. Chem. 1970, 34, 62. (e) Minisci, F.; Porta, O. Adv. Heterocycl. Chem. 1974, 16, 123. (f) Minisci, F.; Vismara, E.; Fontana, F.; Morini, G.; Serravalle, M.; Giordano, C. J. Org. Chem. 1986, 51, 4411. (g) Studer, A.; Bossart, M.; Vasella, T. Org. Lett. 2000, 2, 985. (h) Orito, K.; Uchiito, S.; Satoh, Y.; Tatsuzawa, T.; Harada, R.; Tokuda, M. Org. Lett. 2000, 2, 307. (i) Harrowven, D. C.; Sutton, B. J.; Coulton, S. Org. Biomol. Chem. 2003, 1, 4047. (j) Núñez, A.; Sánchez, A.; Burgos, C.; Alvarez-Builla, J. Tetrahedron 2004, 60, 6217. (k) Curran, D. P.; Keller, A. I. J. Am. Chem. Soc. 2006, 128, 13706.

21) Yanagisawa, S.; Ueda, K.; Taniguchi, T.; Itami, K. Org. Lett. 2008, 10, 4673.

22) Although we hold the temperature at $50{ }^{\circ} \mathrm{C}$, this is the bulk temperature of reaction mixture. As well documented, we assume that the reaction is taking place at high-temperature 'hotspots' that are generated by microwave irradiation. For reviews on the use of microwave in organic synthesis, see: (a) de la Hoz, A.; Díaz-Oritiz, Á.; Moreno, A. Chem. Soc. Rev. 2005, 34, 164. (b) Kappe, C. O. Angew. Chem. Int. Ed. 2004, 43, 6250

23) Arvela, R. K.; Leadbeater, N. E.; Sangi, M. S.; Williams, V. A.; Granados, P.; Singer, R. D. J. Org. Chem. 2005, 70, 161.

24) Deng, G.; Ueda, K.; Yanagisawa, S.; Itami, K.; Li, C.-J. Chem. Eur. J. 2009, 15, 333 .

25) Ban, I.; Sudo, T.; Taniguchi, T.; Itami, K. Org. Lett. 2008, 10, 3607.

26) Selected recent examples:(a) Kuo, W.-J.;Chen, Y.-H.;Jeng, R.-J.; Chan, L.-H.; Lin, W.-P.; Yang, Z.-M. Tetrahedron 2007, 63, 7086. (b) Yabe, M.; Fugono, M. Jpn. Kokai Tokkyo Koho JP2005232159; Chem. Abstr. 143: 266809.

27) Lehuédé, J.; Fauconneau, B.; Barrier, L.; Ourakow, M.; Piriou, A.; Vierfond, J.-M. Eur. J. Med. Chem. 1999, 34, 991.

28) Oxidative $\mathrm{C}-\mathrm{H} / \mathrm{C}-\mathrm{H}$ biaryl coupling catalyzed by $\mathrm{Pd}$ and mediated by $\mathrm{Cu}$ or Ag: (a) Stuart, D. R.; Fagnou, K. Science 2007, 316, 1172. (b) Dwight, T. A.; Rue, N. R.; Charyk, D.; Josselyn, R.; DeBoef, B. Org. Lett. 2007, 9, 3137. (c) Xia, J.-B.; You, S.-L. Organometallics 2007, 26, 4869. (d) Hull, K. L.; Sanford, M. S. J. Am. Chem. Soc. 2007, 129, 11904. (e) Stuart, D. R.; Villemure, E.; Fagnou, K. J. Am. Chem. Soc. 2007, 129, 12072. (f) Li, B.-J.; Tian, S.-L.; Fang, Z.; Shi, Z.-J. Angew. Chem. Int. Ed. 2008, 47, 1115.

29) Oxidative $\mathrm{C}-\mathrm{H} / \mathrm{C}-\mathrm{M}$ biaryl coupling catalyzed by $\mathrm{Pd}$ and mediated by $\mathrm{Cu}$ or Ag: (a) Giri, R.; Maugel, N.; Li, J.-J.; Wang, D.-H.; Breazzano, S. P.; Saunders, L. B.; Yu, J.-Q. J. Am. Chem. Soc. 2007, 129, 3510. (b) Yang, S.; Li, B.; Wan, X.; Shi, Z. J. Am. Chem. Soc. 2007, 129, 6066. (c) Shi, Z.; Li, B.; Wan, X.; Cheng, J.; Fang, Z.; Cao, B.; Qin, C.; Wang, Y. Angew. Chem. Int. Ed. 2007, 46, 5554. (d) Yang, S.-D.; Sun, C.-L.; Fang, Z.; Li, B.-J.; Li, Y.-Z.; Shi, Z.-J. Angew. Chem. Int. Ed. 2008, 47, 1473. (e) Kawai, H.; Kobayashi, Y.; Oi, S.; Inoue, Y. Chem. Commun. 2008, 1464

30) (a) Yanagisawa, S.; Ueda, K.; Sekizawa, H.; Itami, K. J. Am. Chem. Soc. 2009, 131, 14622. (b) Ueda, K.; Yanagisawa, S.; Yamaguchi, J.; Itami, K. Angew. Chem. Int. Ed., in press.

31) Nakano, M.; Tsurugi, H.; Satoh, T.; Miura, M. Org. Lett. 2008, 10, 1851.

32) Roger, J.; Gottumukkala, A. L.; Doucet, H. ChemCatChem 2010, 2, 20.

33) $\mathrm{Pd}$ /bipy catalyst in $\mathrm{C}-\mathrm{H}$ bond arylation: (a) Mori, A.; Sugie, A. Bull. Chem. Soc. Jpn. 2008, 81, 548. (b) Sugie, A.; Kobayashi, K.; Suzaki, Y.; Osakada, K.; Mori, A. Chem. Lett. 2006, 35, 1100.

34) For the use of $\mathrm{Ba}(\mathrm{OH})_{2}$ in Suzuki-Miyaura coupling, see: Watanabe, T.; Miyaura, N.; Suzuki, A. Synlett 1992, 207. 
Kenichiro Itami (born in 1971) is a Professor of Nagoya University (NU). He received his Ph.D. from Kyoto University in 1998 (Prof Y. Ito). He was a predoctoral researcher at Uppsala University, Sweden in 1997-1998 (Prof. J.-E. Bäckvall). He became an Assistant Professor of Kyoto University in 1998 (with Prof. J. Yoshida), an Associate Professor of NU in 2005 (with Prof. R. Noyori), and a Professor of NU in 2008. Representative Awards: Merck-Banyu Lectureship Award (2008), Minister Award for Distinguished Young Scientists (2006), Mitsui Chemicals Catalysis Science Award of Encouragement (2005), Chemical Society of Japan Award for Young Chemists (2005). Fields: (1) $\mathrm{C}-\mathrm{H}$ bond transformation; (2) programmed synthesis; (3) natural products and bioactive molecules; (4) optoelectronic materials; (5) nanocarbon materials. 